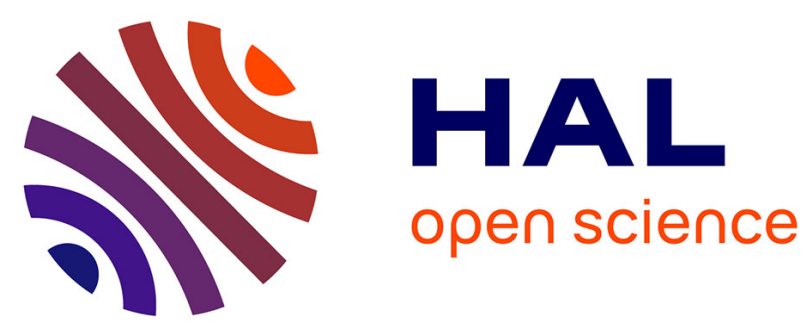

\title{
Anchoring Sites of Fibrillogenic Peptide Hormone Somatostatin-14 on Plasmonic Nanoparticles
}

Eduardo López-Tobar, Belén Hernández, Johanna Gómez, Alexandre Chenal, José Vicente Garcia-Ramos, Mahmoud Ghomi, Santiago Sanchez-Cortes

\section{- To cite this version:}

Eduardo López-Tobar, Belén Hernández, Johanna Gómez, Alexandre Chenal, José Vicente Garcia-Ramos, et al.. Anchoring Sites of Fibrillogenic Peptide Hormone Somatostatin-14 on Plasmonic Nanoparticles. Journal of Physical Chemistry C, 2015, 119 (15), pp.8273-8279. 10.1021/acs.jpcc.5b00485 . pasteur-01406738

\section{HAL Id: pasteur-01406738}

https://hal-pasteur.archives-ouvertes.fr/pasteur-01406738

Submitted on 1 Dec 2016

HAL is a multi-disciplinary open access archive for the deposit and dissemination of scientific research documents, whether they are published or not. The documents may come from teaching and research institutions in France or abroad, or from public or private research centers.
L'archive ouverte pluridisciplinaire HAL, est destinée au dépôt et à la diffusion de documents scientifiques de niveau recherche, publiés ou non, émanant des établissements d'enseignement et de recherche français ou étrangers, des laboratoires publics ou privés.

\section{(1) (1) $\$$}

Distributed under a Creative Commons Attribution - NonCommercial - NoDerivatives 44.0 


\title{
Anchoring Sites of Fibrillogenic Peptide Hormone Somatostatin-14 on Plasmonic Nanoparticles
}

\author{
Eduardo López-Tobar, ${ }^{a}$ Belén Hernández, ${ }^{b}$ Johanna Gómez, ${ }^{c}$ Alexandre Chenal, ${ }^{d}$ \\ José Vicente Garcia-Ramos, ${ }^{a}$ Mahmoud Ghomi, ${ }^{b^{*}}$ Santiago Sanchez-Cortes ${ }^{a^{*}}$
}

${ }^{a}$ Instituto de Estructura de la Materia, IEM-CSIC, Serrano 121, 28006-Madrid, Spain

borbonne Paris Cité, Université Paris 13, Groupe de Biophysique Moléculaire, UFR Santé-MédecineBiologie Humaine, 74 rue Marcel Cachin, 93017 Bobigny cedex, France

${ }^{c}$ Laboratorio de Espectroscopia Atomica y Molecular, Universidad Industrial de Santander, Carrera 27, Calle 9, Bucaramanga, Colombia

${ }^{\mathrm{d} I n s t i t u t ~ P a s t e u r, ~ U n i t e ́ ~ B i o c h i m i e ~ d e s ~ I n t e r a c t i o n s ~ M a c r o m o l e ́ c u l a i r e s, ~ U M R ~ C N R S ~ 3528, ~ 25, ~ R u e ~ d u ~}$ Docteur Roux, 75724 Paris cedex 15, France

${ }^{*}$ Corresponding authors: E-mail: ssc@iem.cfmac.csic.es and mahmoud.ghomi@univ-paris13.fr 
ABSTRACT: Despite numerous investigations devoted to the control of peptide and protein self-assemblies using nanostructured materials, the molecular details of the peptide-material interaction sites remain still under debate. Here, we suggest a solution by using jointly the middle- and low wavenumber regions of surface-enhanced Raman spectra. To achieve our goal, adequately prepared gold and silver colloids, of which the nanofabrication was controlled by means of zeta potential and extinction spectra were used to enhance the Raman signal arising from a natural fibrillogenic peptide hormone, somatostatin-14, at very low $\left(10^{-6}\right.$-to- $\left.10^{-8} \mathrm{M}\right)$ concentrations. Transmission electron microscopy has revealed that the interacting partners are involved in a mutual aggregation process. In fact, while the presence of plasmonic colloids facilitates the aggregation of the peptide, leading to the formation of the so-called "corona" around nanoparticles, we could observe the appearance of relatively large size peptide-nanoparticle agglomerates in solution. However, the comparison between the data obtained from gold and silver nanoparticles is consistent with the fact that the nature of metal surface, as well as its ionic coverage, considerably affects the peptide binding and subsequent aggregation process. Furthermore, this work led us to conclude that the adsorption of somatostatin-14 on silver nanoparticles is rendered possible through an ionic pair interaction, whereas its anchoring on gold nanoparticles occurs by a direct binding, in which the metal atom and the nitrogen of the unique peptide tryptophan residue are involved. 


\section{INTRODUCTION}

Primarily elaborated for their remarkable physicochemical features, nanoparticles (NPs) have rapidly been identified for their possible applications in the field of biology and medicine. ${ }^{1}$ NPs are basically appreciated for their large surface/volume ratio, offering them the possibility to be employed either for accelerating or for inhibiting certain biological processes. In this framework, a series of reports have highlighted the use of selected NPs for controlling protein self-assemblies taking part in human amyloid disorders. ${ }^{2-6}$ To mention a few characteristic examples, we can emphasize the application of (i) organic NPs of NIPAM/BAM copolymer for accelerating the aggregation of human $\beta 2$-microglobulin protein, ${ }^{7}$ (ii) inorganic NPs, such as those elaborated either from CdTe for preventing the fibrillation, ${ }^{8}$ or from uniform maghemite $\gamma-\mathrm{Fe}_{2} \mathrm{O}_{3}$ NPs for accelerating/inhibiting the fibrillation ${ }^{9}$ of amyloid $\beta(\mathrm{A} \beta)$ peptides involved in Alzheimer's disease, (iii) metallic gold NPs which have shown a large spectrum of action including the inhibition of the aggregation of short size $A \beta$ peptides, ${ }^{10}$ the acceleration of fibrillation of cysteine-free peptides, ${ }^{11}$ and finally the retardation of insulin fibrillogenesis process. ${ }^{\mathbf{1 2}}$

Taking into account the large enhancement of the electromagnetic radiation induced by the so-called plasmon resonance effect, we focus here on gold and silver NPs and their particular use in surface enhanced Raman spectroscopy (SERS). This spectroscopic technique is widely used for its ability to detect very low traces of organic molecules in solution, when they are adsorbed on the surface of plasmonic NPs. ${ }^{13,14}$ SERS can also be used as a tool for probing the binding sites of the adsorbed molecules by means of the vibrational markers arising from the molecular groups located in the vicinity, or at the surface of NPs. Herein, SERS data, as well as those from other techniques, were collected from a natural cyclic tetradecapeptide, somatostatin-14 (SST-14) (Scheme 1) adsorbed on Ag or Au NPs. We should briefly recall numerous investigations devoted to the description of the biological and medical importance 
of SST-14 (and its synthetic analogues), regarding its key role in the inhibition of the release of growth hormone $(\mathrm{GH})$, thyroid-stimulating hormone (TSH), insulin and glucagon. ${ }^{15-17}$ However, the choice of SST-14 in the present work was also related to its physicochemical and structural dynamics in aqueous media. (i) Close to physiological $\mathrm{pH}$, this peptide presents a cationic character thanks to the three positive charges borne by the ammonium $\left(\mathrm{NH}_{3}{ }^{+}\right)$ groups located either at its $\mathrm{N}^{\text {ter }}$ position or on the side chain head groups of its $\mathrm{Lys}^{4}$ and $\mathrm{Lys}^{9}$ residues. This feature might obviously facilitate the binding of this peptide to plasmonic NPs covered by negatively charged ions. (ii) Mainly induced by the polar/apolar balance of its amino acid residues, the large size loop of SST-14 was shown to be unstructured at submillimolar concentrations, ${ }^{\mathbf{1 8 , 1 9}}$ revealing a progressive structuring trend upon increasing concentration over the millimolar range. Especially, in the 20-to-60 mM range SST-14 was shown to form high order self-assemblies, referred to as nanofibrils, spherulites and nanofibers. ${ }^{\mathbf{2 0 , 2 1}}$ Hence, SST-14 can be considered as a simple and attractive example for analyzing its possible aggregation around plasmonic NPs. Previously, the formation and time evolution of protein aggregates, referred to as "protein corona", around organic ${ }^{22}$ and metallic ${ }^{23}$ nanoparticles, were described. Hereafter, we use the term "corona" for referring to the aggregates formed by SST-14 around plasmonic NPs.

\section{EXPERIMENTAL METHODS}

SST-14 Samples. Lyophilized powder of SST-14 was purchased from Sigma-Aldrich. All samples were prepared at room temperature using purified MilliQ water. Successive dilutions of the initial stock solutions of SST-14 prepared at $10^{-2} \mathrm{M}$ (for classical Raman spectroscopy), allowed us to reach required concentrations for other experiments. 
Silver Nanoparticles. $300 \mu \mathrm{L}$ of a sodium hydroxide solution $(1 \mathrm{M})$ was added to $90 \mathrm{~mL}$ of a $6 \times 10^{-2} \mathrm{M}$ hydroxylamine hydrochloride solution. Then $10 \mathrm{~mL}$ from a $1.11 \times 10^{-3}$ silver nitrate aqueous solution were added dropwise to the mixture under vigorous stirring. A brown silver colloid was obtained with a final $\mathrm{pH}$ 5.5. Ag NPs were aged 24 hours. The final NPs displayed an average diameter of $35 \mathrm{~nm}$.

Gold Nanoparticles. $50 \mathrm{~mL}$ of $\mathrm{HAu} \mathrm{Cl}_{4} 2 \%$ (by weight) was heated to boiling before addition of a variable volume (V) of $\mathrm{Na}_{3}$-citrate $1 \%$ (by weight). ${ }^{24} \mathrm{Au}$ NPs with approximate diameters ranging between 15 and $150 \mathrm{~nm}(15,50,100$ and $150 \mathrm{~nm})$ were prepared by using the following citrate solution volumes: $\mathrm{V}=1.00,0.50,0.20$ and $0.15 \mathrm{~mL}$. Finally, they were aged two weeks before use.

Zeta Potential Values of NPs. Electrophoretic mobility measurements were performed as described previously. ${ }^{\mathbf{2 5 , 2 6}}$ The experiments were done at $25{ }^{\circ} \mathrm{C}$ on a NanoZS instrument (Malvern Instrument Ltd, Malvern, UK) in DTS1060 cuvettes. The quality of the instrumentation was checked using the standard DTS1230. Intensity was always kept below 5 $\mathrm{mA}$, irrespectively of the applied voltages (from 30 to $100 \mathrm{~V}$ ), as the conductivities of the various NP samples were all below $0.5 \mathrm{mS} . \mathrm{cm}^{-1}$, due to the low ionic strength of the buffers. The quality criteria to keep a measurement were based on: (i) the zeta quality factor (signalto-noise ratio of the frequency shift); (ii) the mean count rate that should not change throughout the duration of the data acquisition; (iii) the quality of the phase plot (radian amplitude and frequency) and the Fourier-transformed of the phase plot. The acceptable electrophoretic mobility measurements were averaged and the standard deviation was computed. As described previously, ${ }^{26}$ the electrophoretic mobility $\mu_{\mathrm{e}}$ was converted to Zeta potential $\zeta$ according to the Hückel-Onsager-Henry equation, $\zeta=\frac{3 \eta_{\mathrm{s}} \mu_{\mathrm{e}}}{2 \varepsilon_{0} \varepsilon_{\mathrm{d}} \mathrm{F}\left(\kappa \mathrm{R}_{\mathrm{p}}\right)}$, where the 
electrophoretic mobility is expressed in $\mathrm{m}^{2} \cdot \mathrm{V}^{-1} \cdot \mathrm{s}^{-1}$ (or $\mu \mathrm{m} \cdot \mathrm{cm} \cdot \mathrm{V}^{-1} \cdot \mathrm{s}^{-1}$ ), the zeta potential in $\mathrm{V}$, the buffer viscosity in $\mathrm{kg} \cdot \mathrm{m}^{-1} \cdot \mathrm{s}^{-1}$ (or in $\mathrm{cP}$ ), the permitivity of free space $\varepsilon_{0}\left(8,85410^{-12}\right.$ $\mathrm{C}^{2} \cdot \mathrm{J}^{-1} \cdot \mathrm{m}^{-1}$ ) and the medium dielectric constant $\varepsilon_{\mathrm{d}}=78.54$ at $25^{\circ} \mathrm{C}$. Consequently, the above equation can be simplified for the experiments performed at $25^{\circ} \mathrm{C}$ as: $\zeta=\frac{21.57 \eta_{\mathrm{s}} \mu_{\mathrm{e}}}{\mathrm{F}\left(\kappa \mathrm{R}_{\mathrm{p}}\right)}$, in which the Henry's function is given by: $F\left(\kappa R_{p}\right)=1+\frac{0.5}{1+e^{A[1-\log (\kappa R p)]}}$, with $R_{p}$ representing the particle radius, and $\kappa$ the inverse screening length (Debye length in $\mathrm{nm}^{-1}$ ) defined as: $\kappa=\sqrt{\frac{2 \mathrm{~N}_{\mathrm{A}} \mathrm{e}^{2} \mathrm{I}}{1000 \varepsilon_{0} \varepsilon_{\mathrm{d}} \mathrm{k}_{\mathrm{B}} \mathrm{T}}}$, where I (in mol. $\mathrm{L}^{-1}$ ) is the ionic strength. The inverse screening length can also be simplified at $25^{\circ} \mathrm{C}$ as: $\kappa=3.27 \sqrt{\mathrm{I}}$. The Zeta potential as a function of the particle distance, $\varphi(\mathrm{x})$, was estimated using the Debye Hückel ionic atmosphere: $\varphi(\mathrm{x})=\varphi(0) \mathrm{e}^{-\mathrm{kx}}$, with $\mathrm{x}$ representing the distance from the surface, considering that the zeta potential corresponds to the electric potential $\varphi(0)$ at $0.2 \mathrm{~nm}$ from the particle surface, a reasonable assumption proposed by McLaughlin.

Transmission Electron Microscopy. TEM images were taken at room temperature using a JEOL JEM-2010 with an acceleration voltage of $200 \mathrm{kV}$. The samples were prepared by depositing $10 \mu \mathrm{L}$ of the suspension containing NPs or SST-14/NPs complexes on carbon coated $\mathrm{Cu}$ grids (ref. $\mathrm{G} 400-\mathrm{Cu}$ ).

Extinction Spectra. UV-Vis absorption spectra of colloids were recorded from $400 \mathrm{~nm}$ to $800 \mathrm{~nm}$, on a Shimadzu 3600 spectrometer by using quartz cells, $1 \mathrm{~cm}$ optical path. Samples were diluted 30\% in MilliQ water (volume/volume). 
Surface-Enhanced Raman Spectra. Data were collected on a Renishaw Raman InVia spectrometer equipped with an electrically cooled CCD camera. Samples were excited by means of the $632.8 \mathrm{~nm}$ and the $785 \mathrm{~nm}$ lines provided by He-Ne and diode lasers with an output power of 25 and $18 \mathrm{~mW}$ at the sample, and a 1200 grooves/nm holographic grating. The spectral resolution was $2 \mathrm{~cm}^{-1}$, with a total acquisition of 10 seconds for each SERS spectrum.

Classical Raman Spectra. Classical Raman spectra were collected by exciting with the $488 \mathrm{~nm}$ line of an $\mathrm{Ar}^{+}$laser (Spectra Physics), $50 \mu \mathrm{L}$ of solution placed in a suprasil quartz cell (5 mm path length). The exciting power at the sample was $\sim 250 \mathrm{~mW}$. The scattered light, collected at $90^{\circ}$ with respect to the incident beam, was analyzed on a Jobin-Yvon T64000 spectrograph in a single mode configuration, equipped with a 1200 grooves/mm holographic grating and a holographic notch filter. A liquid nitrogen cooled CCD detection system (Spectrum One, Jobin-Yvon) was used to collect Raman data. The effective spectral slit width was set to $5 \mathrm{~cm}^{-1}$.

\section{RESULTS AND DISCUSSION}

Main Characteristics of Plasmonic Nanoparticles. The cyclic structure of SST-14 is maintained by a disulfide (S-S) linkage between its $\mathrm{Cys}^{3}$ and $\mathrm{Cys}^{14}$ residues (Scheme 1). To preserve the structural integrity of this peptide, a special attention was paid to avoid the breakdown of this S-S bond, particularly on Ag NPs, by following the procedure described recently. ${ }^{24}$ To establish our nanofabrication protocol, the main parameters to be adjusted were (i) the metal nature and reduction protocol, (ii) the adequate size of Ag and Au NPs for SERS 
experiments. Here, the SERS sensitivity was maximized by tuning the excitation wavelength over the plasmon resonance band, which depends on the size of elaborated NPs.

The zeta potential values, deduced from electrophoretic mobility measurements (see Material and Methods for details) in the solutions containing the adequate NPs, confirm their negatively charged coverage (Figure 1). The corresponding value estimated at the surface of Ag NPs $(\sim-45 \mathrm{mV})$ (Figure 1B) is about twofold lower than that corresponding to Au NPs $(\sim-21 \mathrm{mV})$ (Figure 1A). After the Stern layer, at the Debye length $(1 / \kappa)<4 \mathrm{~nm}$, corresponding to the sliding plane of the interfacial double layer, the zeta potential value increases to -15 and $-8 \mathrm{mV}$ in $\mathrm{Ag}$ and $\mathrm{Au}$, respectively. This indicates that both types of colloids can exhibit on their hydrodynamic surfaces significant attractive electrostatic interaction with a positively charged molecule such as SST-14. Then, in the diffuse Gouy-Chapman layer, both types of NPs show a rapid zeta potential increase, vanishing at a distance of $\sim 15 \mathrm{~nm}$ from their surface.

Nanoparticles in the Presence of SST-14. TEM images have revealed large size aggregates formed by SST-14 adsorption on plasmonic NPs (Figure 2). The charge screening of the NPs caused by the presence of the peptide should be mainly responsible for the formation of these large agglomerates. However, a net difference can be observed between the two types of aggregates. In fact, monodisperse and large size Au NPs (diameter between 90 and $100 \mathrm{~nm}$ ) (Figure 2A) and polydisperse Ag NPs (diameter between 10 and $50 \mathrm{~nm}$ ) join together for forming the corresponding agglomerates (Figure 2B \& 2D). Reciprocally, the adsorption of the peptide chains leads to the formation of the so-called corona around plasmonic NPs. While, a quite homogeneous peptide layer, with a depth of $\sim 8 \mathrm{~nm}$, is formed around $\mathrm{Au}$ NPs (Figure 2C), a variable one, of which the thickness can increase up to $20 \mathrm{~nm}$, 
is found around Ag NPs (Figure 2E). This effect corroborates naturally the non-identical zeta potential values measured at the surface of Au and Ag NPs (Figure 1).

Plasmon Resonance of Nanoparticles Activated by SST-14 Adsorption. In a general manner, the position of the plasmon resonance band depends on the size of NPs, as well as on the type of aggregating agents $\left(\mathrm{AgNO}_{3}, \mathrm{NaCl}\right.$, etc $) .{ }^{27} \mathrm{Here}$, no aggregating agent was added in order to activate $\mathrm{Ag}$ and Au colloids. In other words, SST-14 was capable of inducing alone the aggregation of plasmonic NPs. The optimal SERS sensitivity was achieved by using large size $\mathrm{Au}$ NPs, consistent with a plasmon resonance redshift from 545 to $780 \mathrm{~nm}$ observed upon increasing peptide concentration (Figure 3A). Correspondingly, the adsorption of SST-14 on polydisperse Ag NPs prepared by means of hydroxylamine, leads to a plasmon resonance redshift from 405 to $630 \mathrm{~nm}$ (Figure 3B). It should be remarked that no SERS signal could be obtained on Ag colloids in the presence of citrate ions used as reductor, presumably because of the competition between the citrate ion binding and the peptide chain adsorption to $\mathrm{Ag}$ surface.

Search of Optimal Conditions for Recording SERS Spectra. The position of the plasmon resonance bands displayed in Figure 3, justify the choice of the excitation wavelengths 632.8 and $785 \mathrm{~nm}$ for recording the SERS spectra on Ag and $\mathrm{Au}$ colloids, respectively. Figure S1 (Supplementary Information) shows two typical SERS spectra obtained in the whole spectral region (4000-400 $\mathrm{cm}^{-1}$ ) from SST-14 adsorbed on Ag and Au colloids. To show the representative range of peptide concentration giving rise to good quality signal-to-noise ratio, we have displayed the intensity ratio between the strongest Phe marker mode (at $1003 \mathrm{~cm}^{-1}$ ) and the characteristic water bending mode (at $3400 \mathrm{~cm}^{-1}$ ) as a function of concentration in Figure S2 (Supplementary Information). It is worth mentioning that the shape 
of the corresponding curves allows getting insight into peptide-peptide and peptide-metal interactions, thus revealing the differences between the adsorption mechanisms corresponding to different colloid types. ${ }^{\mathbf{2 8 , 2 9}}$ While a Langmuir curve suggesting the prevalence of the peptide interaction with $\mathrm{Au}$ surface fits the observed data (Figure S1-A, Supporting information), a sigmoidal behavior proving the existence of strong SST-14 intermolecular interactions is deduced from Ag colloids (Figure S1-B, Supporting Information).

Fingerprints of Interaction Sites Observed in Middle Wavenumber Region. The SERS spectra recorded at $10^{-6} \mathrm{M}$ on Au NPs and at $5 \times 10^{-7} \mathrm{M}$ on Ag NPs are displayed in Figure 4 in the middle spectral region (1800-300 $\left.\mathrm{cm}^{-1}\right)$, as compared to the classical Raman spectrum recorded in the bulk at a $\sim 10^{4}$ times higher concentration. It should be reminded that due to their conjugated $\pi$-electron systems, aromatic residues provide the major part of strong Raman markers in classical ${ }^{18,19}$ and SERS $^{30}$ spectra.

As we have already mentioned, precaution was made to preserve the integrity of the disulfide linkage by the use of adequately prepared Ag NPs. Our nanofabrication had proved its adequacy in the case of cystine (a simple model compound formed by joining two cystines through a S-S bridge) ${ }^{24}$ Disulfide integrity can be proved by the presence of a Raman band around $500 \mathrm{~cm}^{-1}$ resulting from the $\mathrm{S}-\mathrm{S}$ bond stretching motion. ${ }^{31}$ It should be also emphasized that in aqueous solution the contribution of the other modes (such as those arising from the low wavenumber bending vibrations of aromatic residues) to the Raman intensity around $500 \mathrm{~cm}^{-1}$, is negligible. ${ }^{31}$ In the present work, the presence of the band at $498 \mathrm{~cm}^{-1}$ confirms that the disulfide bridge is maintained on Ag NPs (Figure 4 middle). However, the weak relative intensity of this marker indicates that the S-S bond is placed quite far from the metal surface. Furthermore, except the changes observed in the $\operatorname{Trp}^{8}$ residue characteristic 
mode at $1551 \mathrm{~cm}^{-1}$, as well as in the aliphatic groups at $1458-1438 \mathrm{~cm}^{-1}$, the SERS spectrum on Ag NPs provides globally a similar shape as that observed in the bulk (Figure 4 bottom).

On the contrary, the binding of SST-14 to Au NPs is followed by drastic changes in the wavenumbers and relative intensities of the $\operatorname{Trp}^{8}$ Raman markers (shown by red arrows in Figure 4 top). These changes are consistent with a close contact of the $\operatorname{Trp}^{8}$ residue with $\mathrm{Au}$ colloids. It should be noted that whatever the type of metallic NPs, the six characteristic Phe markers (located at $\sim 1606,1586,1207,1031,1003$ and $622 \mathrm{~cm}^{-1}$ ), ${ }^{32}$ remain unchanged. In other words, any close contact of the Phe residues with Au NPs can be expected based on SERS data.

Fingerprints of Interaction Sites Observed in Low Wavenumber Region. The low wavenumber spectral region, i.e. below $300 \mathrm{~cm}^{-1}$, provides complementary information on the binding mechanism of the peptide to plasmonic NPs. This region displays the bond stretching vibrations in which the metal atom is directly involved.

Figure 5A clearly shows that nude Au NPs does not present any Raman band below 300 $\mathrm{cm}^{-1}$, whereas the peptide adsorption on these particles makes appear a characteristic band peaking at $253 \mathrm{~cm}^{-1}$, previously assigned to Au-N stretching vibration. ${ }^{33}$ Putting together this observation and the SERS data in the middle wavenumber region (Figure 4 top, see preceding section for details), we conclude that the $\operatorname{Trp}^{8}$ residue is involved in a direct interaction with $\mathrm{Au}$ NPs through its unique $\left(\mathrm{N}_{\varepsilon}\right)$ atom, as suggested in Figure 6A. Other evidences, brought about by the middle wavenumber region (Figure 4 top), confirm this particular interaction. For instance (i) the drastic enhancement of the Raman band at $1112 \mathrm{~cm}^{-1}$, ascribed to the angular bending motions located around the $\mathrm{N}_{\varepsilon}$ atom of the Trp indole ring, ${ }^{34}$ (ii) the change in the characteristic Trp Raman doublet (observed at 1362-1342 $\mathrm{cm}^{-1}$ in the bulk, Figure 4 bottom), joining together for forming a single band at $1352 \mathrm{~cm}^{-1}$ (Figure 4 top); (iii) the 
wavenumber downshifts $880 \rightarrow 873 \mathrm{~cm}^{-1}$ and $760 \rightarrow 752 \mathrm{~cm}^{-1}$ occurring in two other Trp bands in going from the bulk (Figure 4 bottom) to Au NPs (Figure 4 top).

In contrast, Figure 5B reveals a completely different situation for the binding to Ag NPs. Thanks to the presence of $\mathrm{Cl}^{-}$ions around silver colloids (see Material and Methods for details), a Raman band is observed at $245 \mathrm{~cm}^{-1}$, previously ascribed to $\mathrm{Ag}-\mathrm{Cl}^{-}$bond stretching mode. ${ }^{35,36}$ In the presence of SST-14, a lower wavenumber component at $\sim 220 \mathrm{~nm}$ appears, consistent with the perturbations occurring at the surface of Ag NPs by the presence of SST14. Evidently, this interaction should be preferably of electrostatic character, i.e. with one of the three cationic $\left(\mathrm{NH}_{3}{ }^{+}\right)$sites of the peptide. Figure 6B shows side by side three schemes suggesting possible binding of the peptide through an ionic pair interaction of $\mathrm{Ag}-\mathrm{Cl}^{-} \ldots \mathrm{NH}_{3}{ }^{+}$ type.

Toward a primary description of peptide corona around plasmonic NPs. The question raised here is to see whether the adsorption models suggested for individual peptides (Figure 6), can be compatible with the formation of their aggregation around metallic NPs. For this, we can consider the aggregation models suggested for SST-14 in the bulk, based on the recent spectroscopic and imaging observations in highly concentrated solutions (20-to-60 mM)..$^{\mathbf{2 0 2}}$ Following this models, the first stage of the SST-14 self-assembly is a nonofibril, obtained by a side-by-side arrangement of individual peptides, stabilized by the lateral amino acid interactions. This nanofibril can bind from one side ( $\operatorname{Trp}^{8}$ residues) to an Au NP, while its other side $\left(\mathrm{N}^{\text {ter }}\right.$ ammonium groups) can establish favorable interactions with an Ag NP. Hence, such a fibril can be a good model for the formation of the first peptide layer appearing upon aggregation around a plasmonic colloid. However, estimating by $\sim 2 \mathrm{~nm}$ the largest dimension of an individual SST-14 (i.e. from its $\mathrm{N}^{\text {ter }}$ to the top of its loop), and considering the thickness of the peptide aggregates (TEM images, Figure 2), it can be easily understood 
that more than one peptide layer should be present in a given corona. Again, as suggested recently, ${ }^{\mathbf{2 0 , 2 1}}$ higher order SST-14 aggregates can appear in the bulk through the autoassociation of the above mentioned nanofabrils, either stabilized by $\pi$-interactions between their top $\operatorname{Trp}^{8}$ residues, or through the H-bonds formed between their $\mathrm{N}^{\text {ter }}$ residues. One or the other of these two suggested types of nanofibril associations might provide an acceptable description of the peptide corona observed around plasmonic colloids. Further experiments based on high resolution electron microscopy images would be necessary to confirm the above mentioned models.

\section{CONCLUSIONS}

In a recent investigation, the joint use of the middle wavenumber SERS spectra and molecular dynamics for analyzing protein-drug interactions, was emphasized. ${ }^{37}$ Here, we pointed out the advantages of using jointly the middle- and low wavenumber regions for probing the interaction sites of a cationic peptide on plasmonic NPs. In this framework, the usefulness of the data obtained from electrophoretic mobility, extinction spectra and transmission electron microscopy, allowing determination of the charge and size of NPs, as well as the main characteristics of their complexes with SST-14, has also been highlighted.

Undoubtedly, the high affinity of SST-14 to bind to Au and Ag NPs is mainly responsible for achieving a very good signal/noise ratio in the SERS spectra recorded at very low peptide concentration. However, the differences encountered between the binding mechanisms of this peptide to the two types of plasmonic NPs are consistent with the fact that the metal nature and its ionic coverage affect the peptide binding and its subsequent aggregation process. In this work, we have also taken benefit from the presence of the corona formed by the peptide aggregation around NPs, as well as from the large size peptide/NP aggregates, in order to 
enhance the SERS intensity. ${ }^{38}$ As a consequence, a cationic peptide such as SST-14, can play the role of activator in the adsorption/aggregation feedback process.

This work opens the discussion on the establishment of systematic protocols allowing controlling the coordination and binding sites of peptides and proteins on plasmonic colloids. Further investigations would confirm the applicability of the presently elaborated NPs to other cationic peptides, while other nanofabrication protocols should be suggested for facilitating the adsorption of negatively charged or neutral peptide chains.

\section{ACKNOWLEDGMENTS}

The authors would like to gratefully thank CSIC for the Project I-LINK 0646, facilitating the collaboration between the Spanish and French groups. This work was also supported by the Spanish Ministerio de Ciencia e Innovación (grant FIS2010-15405). J. G. thanks for a fellowship from COLCIENCIAS.

\section{SUPPORTING INFORMATION}

Figures S1 and S2, as well as the full description of reference (37), have been provided. This information is available free of charge via the Internet at http://pubs.acs.org.

\section{REFERENCES}

(1) Salata, O. Application of Nanoparticles in Biology and Medicine. J. Nanotechnology 2004, 2, 3

(2) Zaman, M.; Ahmad, E.; Qadeer, A.; Rabbani, G.; Hasan Khan, R. Nanoparticles in Relation to Peptide and Protein Aggregation. Int. J. Nanomedicine 2014, 9, 899-912.

(3) Kelly, J. W. The Environmental Dependency of Protein Folding Best Explains Prion and Amyloid Diseases. Proc. Natl. Acad. Sci. USA 1998, 95, 930-932.

(4) Kelly, J. W. The Alternative Conformations of Amyloidogenic Proteins and Their Multi-Step Assembly Pathways. Curr. Opin. Struct. Biol. 1998, 8, 101-106. 
(5) Dobson, C. M. The Structural Basis of Protein Folding and Its Links with Human Diseases. Phil. Trans. Roy. Soc. Lond. B 2001, 356, 133-145.

(6) Cohen, S. A. I.; Linse, S.; Luheshi, L. M.; Hellstrand, E.; White, D. A.; Rajah, L.; Otzen, D. E.; Vendruscolo, M.; Dobson, C. M.; Knowles, T. P. J. Proliferation of Amyloid- $\beta 42$ Aggregates Occurs through a Secondary Nucleation Mechanism. Proc. Natl. Acad. Sci. USA 2013, 110, 9758-9763.

(7) Linse, S.; Cabaleiro-Lago, C.; Xue, W. F.; Lynch, I.; Lindman, S.; Thulin, E.; Radford, S. E.; Dawson, K. A. Nucleation of Protein Fibrillation by Nanoparticles. Proc. Natl. Acad. Sci. USA 2007, 104, 8691-8696.

(8) Yoo, S. I.; Yang, M.; Brender, J. R.; Subramanian, V.; Sun, K.; Joo, N. E.; Jeong, S. H.; Ramamoorthy, A.; Kotov, N. A. Inhibition of Amyloid Peptide Fibrillation by Inorganic Nanoparticle : Functional Similarities with Proteins. Angew. Chem. 2011, 50, 5110-5115.

(9) Skaat, H.; Shafir, G.; Margel, S. Accelaeration of Amyloid- $\beta$ Fibril Formation by PeptideConjugated Fluorescent-Maghemite Nanoparticles. J. Nanopart. Res. 2011, 13, 3521-3534.

(10) Ma, Q.; Wei, G.; Yang, X. Influence of Au Nanoparticles on the Aggregation of Amyloid- $\beta$-(2535) Peptides. Nanoscale 2013, 5, 10397-10403.

(11) Nergiz, S. Z.; Slocik, J. M.; Naik, R. R.; Singamaneni, S. Surface Defect Sites Facilitates Fibrillation: An Insight Into Adsorption of Gold-Binding Peptides on Au (111). Phys. Chem. Chem. Phys. 2013, 15, 11629-11633.

(12) Hsieh, H.; Chang, C. W.; Cho, H. H. Gold Nanoparticles as Amyloid Fibrillogenesis Inhibitors. Coll. Surf. B: Biointerfaces 2013, 112, 525-529.

(13) Aroca, R. Surface-Enhanced Vibrational Spectroscopy, John Wiley \& Sons: Chichester, U.K., 2006.

(14) Moskovits, M. Surface Enhanced Spectroscopy. Rev. Mod. Phys. 1985, 57, 783-826.

(15) Brazeau, P.; Vale, W.; Burgus, R.; Ling, N.; Butcher, M.; Rivier, J.; Guillemin, R. Hypothalamic Polypeptide That Inhibits the Secretion of Immunoreactive Pituitary Growth Hormone. Science 1973, $179,77-79$.

(16) Burgus, R.; Ling, N.; Butcher, M.; Guillemin, R. Primary Structure of Somatostatin, A Hypothalamic Peptide That Inhibits the Secretion of Pituitary Growth Hormone. Proc. Natl. Acad. Sci. USA 1973, 70, 684-688.

(17) Weckbecker, G.; Lewis, I.; Albert, R.; Schmid, H. A.; Hoyer, D.; Bruns, C. Opportunities in Somatostatin Research: Biological, Chemical and Therapeutic Aspects. Nat. Mat. Drug Discov. 2003, 2, 999-1017.

(18) Hernández, B.; Carelli, C.; Coïc, Y. M.; De Coninck, J.; Ghomi, M. Vibrational Analysis of Amino Acids and Short Peptides in Aqueous Media. V. The Effect of the Disulfide Bridge on the Structural Features of the Peptide Hormone Somatostatin-14. J. Phys. Chem. B 2009, 113, 1279612803. 
(19) Hernández, B.; Coïc, Y. M.; Baron, B.; Kruglik, S. G.; Pflüger, F.; Cohen, R.; Carelli, C.; Ghomi, M. Low Concentration Structural Dynamics of Lanreotide and Somatostatin-14. Biopolymers 2014, 101, 1019-1028.

(20) van Grondelle, W.; López-Iglesias, C.; Coll, E.; Artzner, F.; Paternostre, M.; Lacombe, F.; Cardus, M.; Martinez, G.; Montes, M.; Cherif-Cheikh, R.; Valéry, C. Spontaneous Fibrillation of the Native Neuropeptide Hormone Somatostatin-14. J. Struct. Biol. 2007, 160, 211-223.

(21) van Grondelle, W.; Lecomte, S.; López-Iglesias, C.; Monero, J. M.; Cherif-Cheikh, R.; Paternostre, M.; Valéry, C. Lamination and Spherulite-Like Compaction of a Hormone's Native Amyloid-like Nanofibrils: Spectroscopic Insights into Key Interactions. Faraday Discuss. 2013, 166, 163-180.

(22) Cedervall, T.; Lynch, I.; Lindman, S.; Berggård, T.; Thulin, E.; Nilsson, H.; Dawson, K.; Linse, S. Understanding the Nanoparticle-Protein Corona Using Methods to Quantify Exchange Rates and Affinities of Proteins for Nanoparticles. Proc. Natl. Acad. Sci. USA 2007, 104, 2050-2055.

(23) Casals, E.; Pfaller, T.; Duschl, A.; Oostingh, G. J.; Puntes, V. Time Evolution of the Nanoparticle Protein Corona. ACS Nano 2010, 4, 3623-3632.

(24) López-Tobar, E.; Hernández, B.; Ghomi, M.; Sanchez-Cortes, S. Stability of the Disulfide Bond in Cystine Adsorbed on Silver and Gold Nanoparticles as Evidenced by SERS Data. J. Phys. Chem. C 2013, 117, 1531-1537.

(25) Sotomayor-Pérez, A. C.; Ladant, D.; Chenal, A. Calcium-Induced Folding of Intrinsically Disordered Repeat-in-Toxin (RTX) Motifs via Changes of Protein Charges and Oligomerization States. J. Biol. Chem. 2011, 286, 16997-17004.

(26) Sotomayor-Pérez, A. C.; Karst, J. C.; Ladant, D.; Chenal, A. Mean Net Charge of Intrinsically Disordered Proteins: Experimental Determination of Protein Valence by Electrophoretic Mobility Measurements. Methods Mol. Biol. 2012, 896, 331-349.

(27) Sanchez-Cortes, S.; Garcia-Ramos, J. V.; Morcillo, G.; Tinti, A. Morphological Study of Silver Colloids Employed in Surface-Enhanced Raman Spectroscopy: Activation When Exciting in Visible and Near-Infrared Regions. J. Coll. Interface Sci. 1995, 175, 358-368.

(28) Izquierdo-Lorenzo, I.; Sanchez-Cortes, S.; Garcia-Ramos, J. V. Adsorption of Beta-Adrenergic Agonists Used in Sport Doping on Metal Nanoparticles: A Detection Study Based on SurfaceEnhanced Raman Scattering. Langmuir 2010, 26, 14663-14670.

(29) Izquierdo-Lorenzo, I.; Garcia-Ramos, J. V.; Sanchez-Cortes, S. Vibrational Characterization and Surface-Enhanced Raman Scattering Detection of Probenecid Doping Drug. J. Raman Spectrosc. 2013, 44, 1422-1427.

(30) Gellini, C.; Sabatino, G.; Papini, A. M.; Muniz-Miranda, M. SERS Study of a Tetrapeptide Based on Histidine and Glycine Residues, Adsorbed on Copper/Silver Colloidal Nanoparticles. $J$. Raman Spectrosc. 2014, 45, 418-423. 
(31) Hernández, B.; Pflüger, F.; López-Tobar, E.; Kruglik, S. G.; Garcia-Ramos, J. V.; SanchezCortes, S.; Ghomi, M. Disulfide Linkage Raman Markers: A Reconsideration Attempt. J. Raman Spectrosc. 2014, 45, 657-664.

(32) Hernández, B.; Pflüger, F.; Kruglik, S. G.; Ghomi, M. Characteristic Raman Lines of Phenylalanine Analyzed by a Multiconformational Approach. J. Raman Spectrosc. 2013, 44, 827-833.

(33) Creighton, J. A.; Blatchford, C. G.; Albrecht, M. G. Plasma Resonance Enhancement by Pyridine Adsorbed on Gold and Silver Sol Particles of Size Comparable to the Excitation Wavelength. J. Chem. Soc. Faraday Trans II 1979, 75, 790-798.

(34) Hernández, B.; Pflüger, F.; Adenier, A.; Kruglik, S. G.; Ghomi, M. Vibrational Analysis of Amino Acids and Short Peptides in Hydrated Media. VIII. Amino Acids with Aromatic Side Chains: L-Phenylalanine, L-Tyrosine, and L-Tryptophan. J. Phys. Chem. B 2010, 114, 15319-15330.

(35) Garrell, R. L.; Shaw, K. D.; Krimm, S. Surface Enhanced Raman Spectroscopy of Halide Ions on Colloidal Silver: Morphology and Coverage. Surf. Sci. 1983, 124, 613-624.

(36) Cañamares, M. V.; Garcia-Ramos, J. V.; Gómez-Varga, J. D.; Domingo, C.; Sanchez-Cortes, S. Comparative Study of the Morphology, Aggregation, Adherence to Glass, and SurfaceEnhanced Raman Scattering Activity of Silver Nanoparticles Prepared by Chemical Reduction of $\mathrm{Ag}^{+}$Using Citrate and Hydroxylamine. Langmuir 2005, 21, 8546-8553.

(37) Karthigeyan, D.; Siddhanta, S.; Kishore, H. A.; Perumal, S. S. R. R.; Agren, H.; Sudevan, S.; Bhat, A. V.; Balasubramanyam, K.; Subbegowda, R. K.; Kundu, T. K.; et al. SERS and MD Simulation Studies of a Kinase Inhibitor Demonstrate the Emergence of a Potential Drug Discovery Tool. Proc. Natl. Acad. Sci. USA 2014, 111, 10416-10421.

(38) Wang, X.; Li, M.; Meng, L.; Lin K.; Feng, J.; Huang, T., Yang, Z.; Ren, B. Probing the Location of Hot Spots by Surface-Enhanced Raman Spectroscopy: Toward Uniform Substrates. ACS Nano 2014, $8,528-536$. 


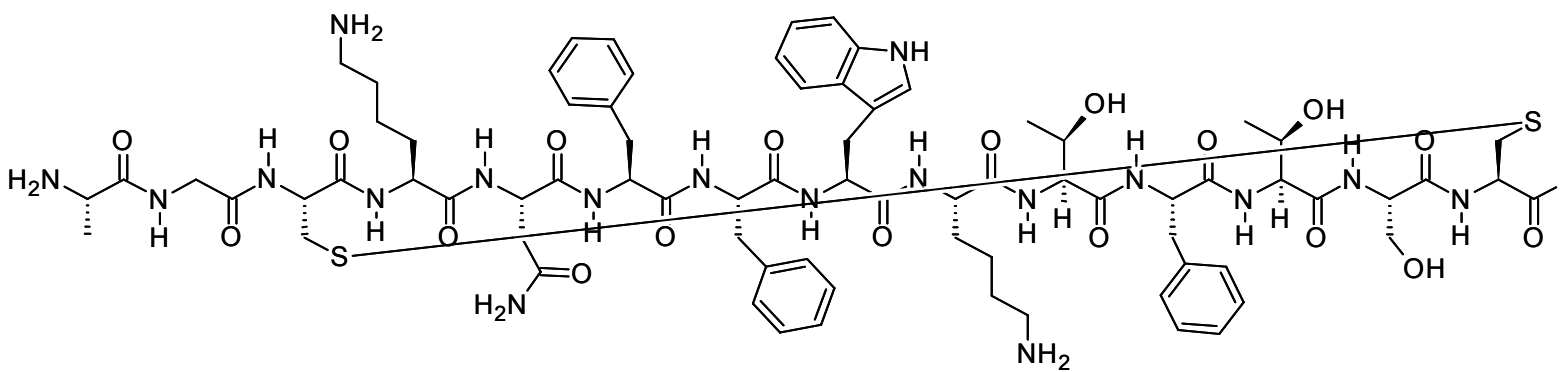

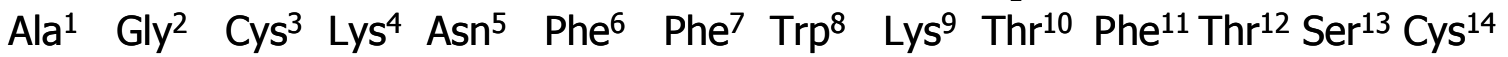

Scheme 1. Amino acid composition and numbering of somatostatin-14. The cyclic structure of the peptide is maintained by a disulfide (S-S) linkage between its $\mathrm{Cys}^{3}$ and $\mathrm{Cys}^{14}$ residues (shown by an extended solid line). 

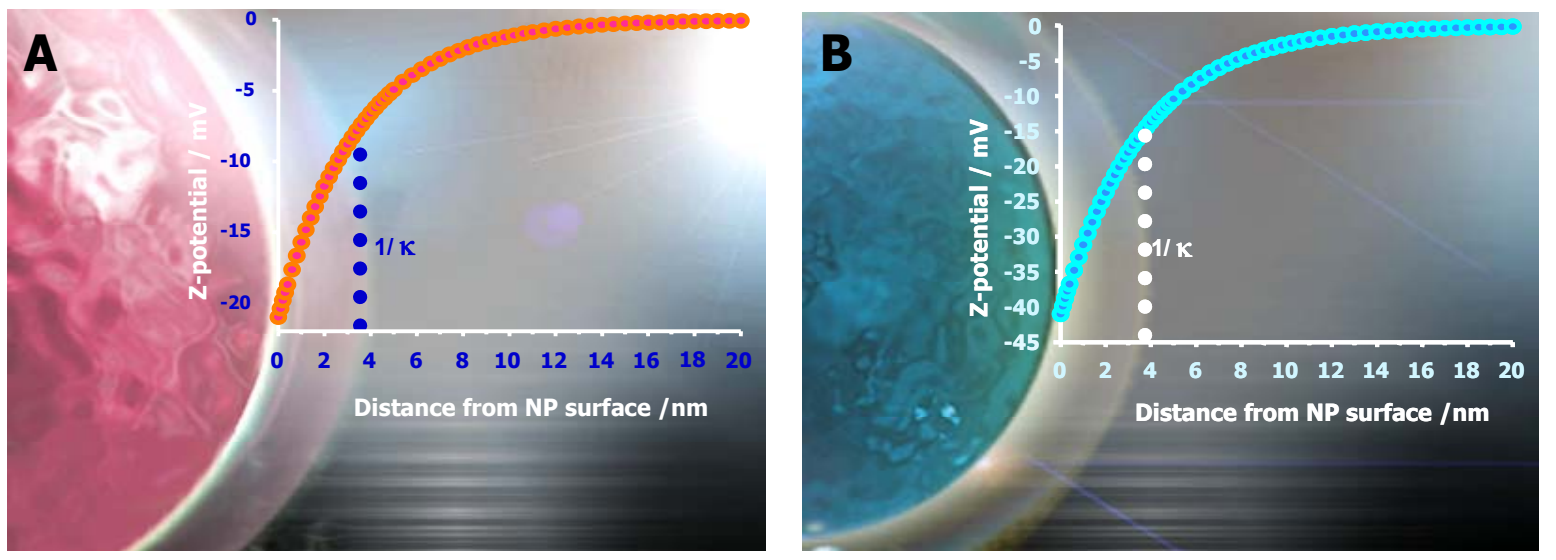

Figure 1. Variation of the Zeta potential as a function of the distance from the surface of plasmonic nanoparticles. (A) and (B) refers to gold and silver colloids, respectively. Zeta potential values and distances are expressed in $\mathrm{mV}$ and $\mathrm{nm}$, respectively. 


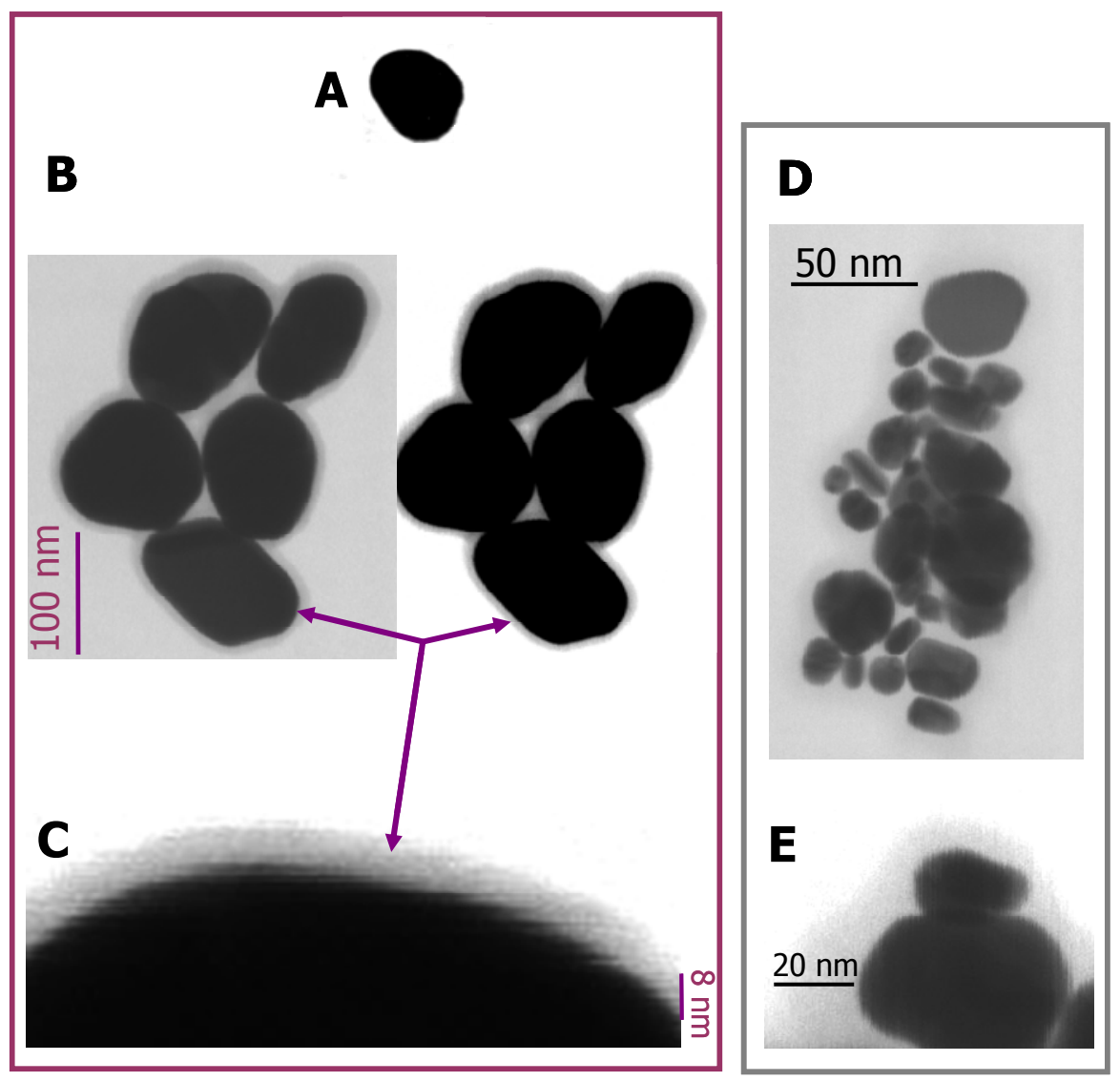

Figure 2. Transmission electron microscopy images of plasmonic nanoparticles. (A) A nude gold nanoparticle. (B) An agglomerate of gold nanoparticles formed in the presence of somatostatin-14, as presented with two different contrasts. (C) Zoom on a gold nanoparticle surrounded by a peptide layer. (D) An agglomerate of silver nanoparticles formed in the presence of somatostatin-14. (E) Zoom on silver nanoparticles surrounded by a peptide layer. 

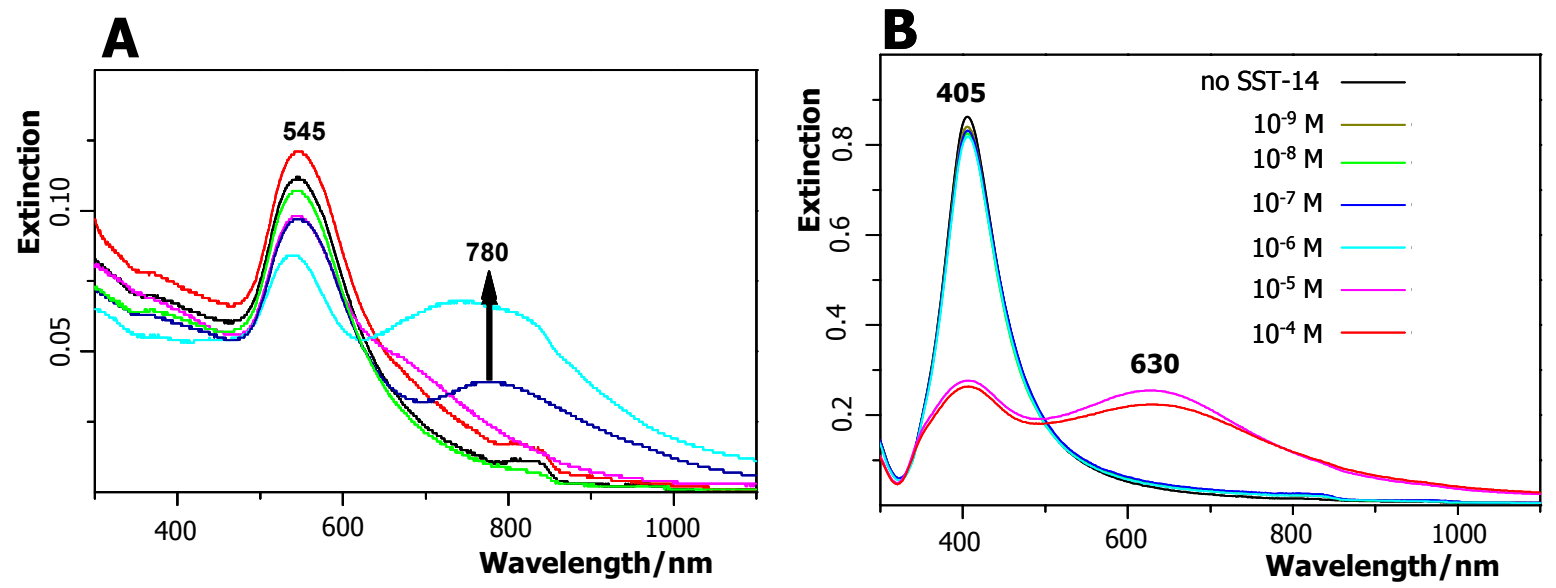

Figure 3. Extinction spectra of plasmonic nanoparticles. Data obtained from the solutions containing gold (A) and silver (B) nanoparticles at different concentrations of somatostatin-14. Color codes corresponding to different concentrations are indicated in frame (B). 


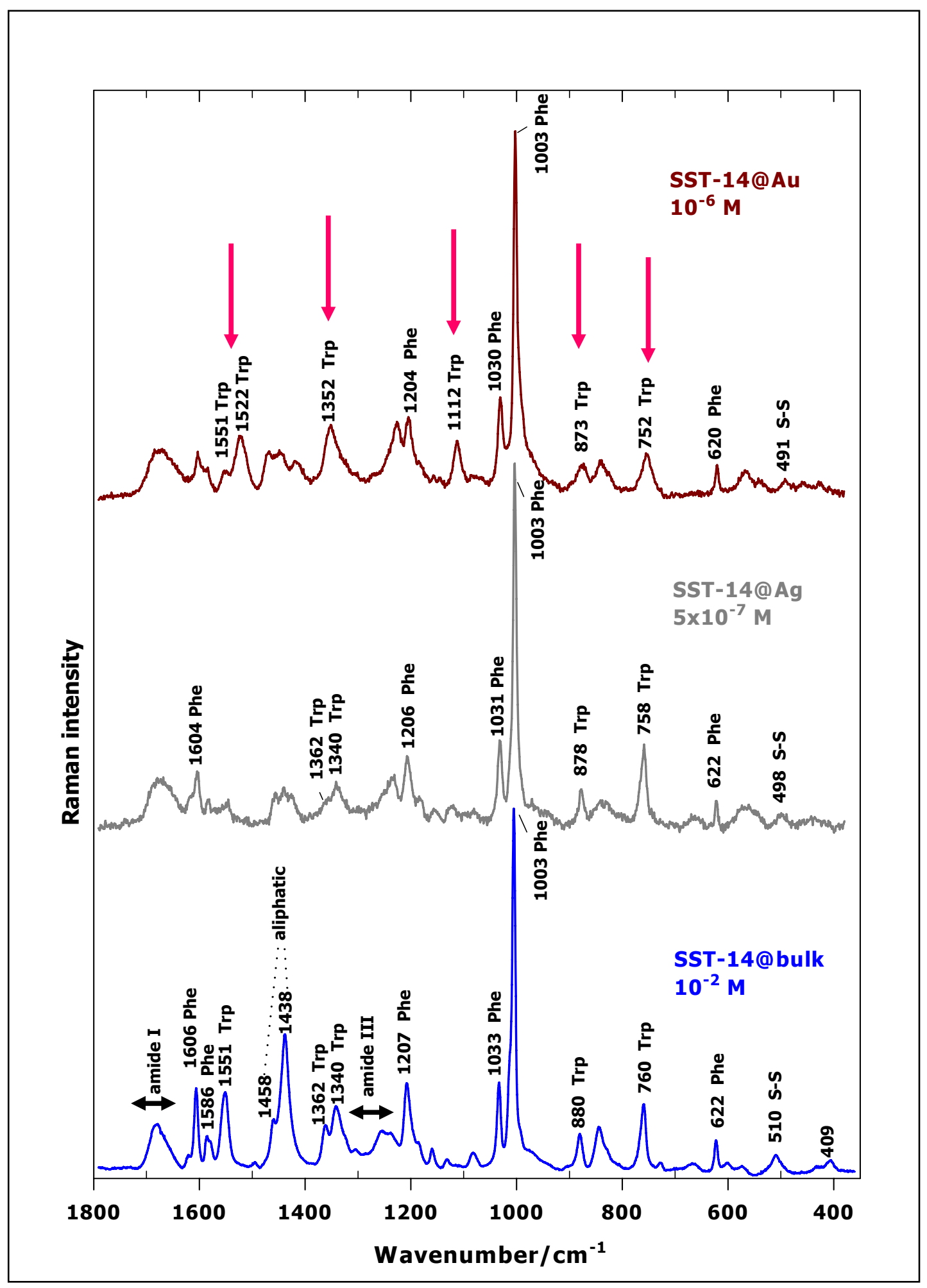

Figure 4. Middle wavenumber $\left(1800-350 \mathrm{~cm}^{-1}\right)$ region of Raman spectra. Bottom, classical Raman spectrum of SST-14 recorded in the bulk $\left(10^{-2} \mathrm{M}\right)$. Middle, SERS spectrum of somatostatin-14 $\left(5 \times 10^{-7}\right.$ $\mathrm{M})$ adsorbed on silver nanoparticles. Top, SERS spectrum of somatostatin-14 $\left(10^{-6} \mathrm{M}\right)$ adsorbed on gold nanoparticles. Trp markers perturbed by the peptide adsorption on gold nanoparticles are shown by red arrows. 
A

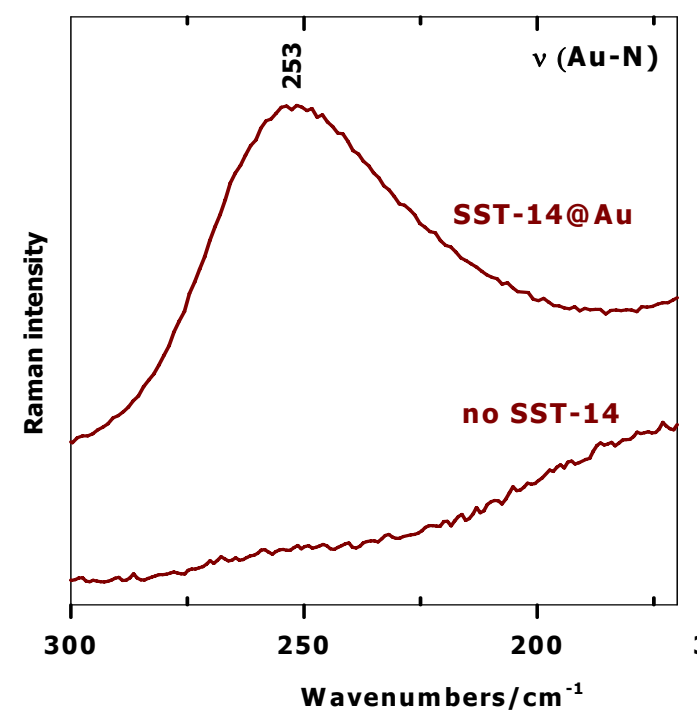

B

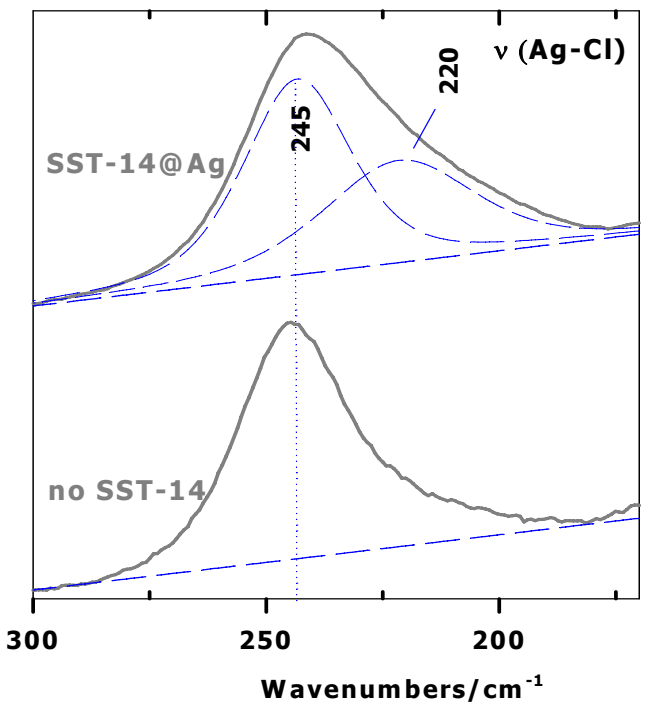

Figure 5. Low wavenumber spectral region of the surface-enhanced Raman spectra. (A) Spectra taken from the solutions containing gold nanoparticles in the absence (bottom) and in the presence (top) of SST-14. (B) Spectra taken from the solutions containing silver nanoparticles either in the absence (bottom) and in the presence (top) of somatostatin-14. Band decomposition is shown in blue colour broken line. 
B
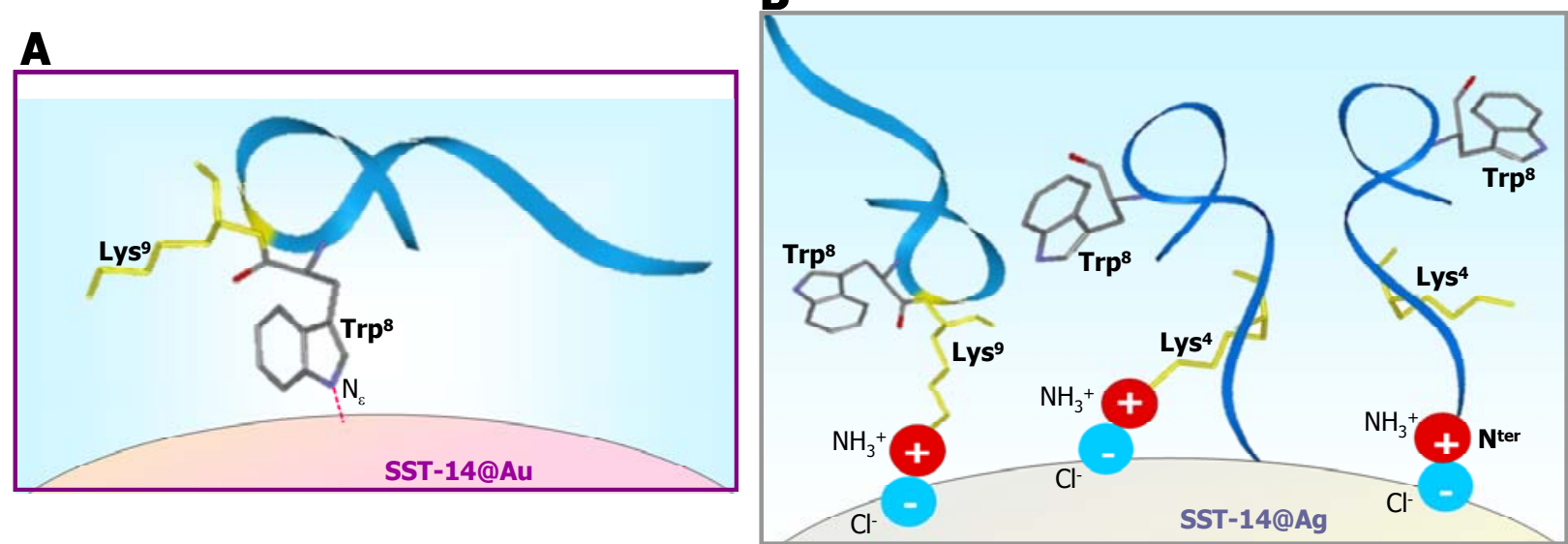

Figure 6. Suggested adsorption schemes of somatostatin-14 on plasmonic nanoparticles. (A) Adsorption via a direct interaction of the $\operatorname{Trp}^{8}$ residue with a gold nanoparticle. (B) Three possible adsorption schemes for binding on a silver nanoparticle. 
TOC

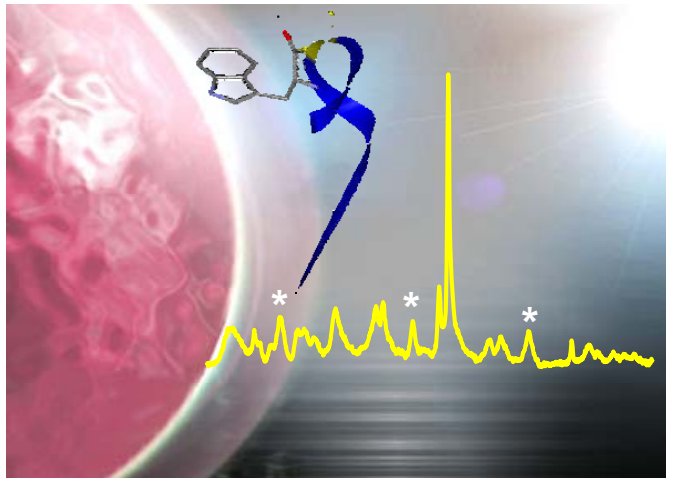

